\title{
Tailoring material properties of cellulose sponges through surface plasma modification for clinical applications
}

\author{
Anne Krüger-Genge ${ }^{\mathrm{a}, *}$, Jörg Bohrisch ${ }^{\mathrm{a}}$, Olivia Mauger ${ }^{\mathrm{a}}$, Sophia Westphal $^{\mathrm{a}}$, \\ Stefanie Klöpzig ${ }^{\mathrm{a}}$, Werner Müller ${ }^{\mathrm{b}}$ and Joachim Storsberg ${ }^{\mathrm{a}}$ \\ ${ }^{\text {a }}$ Fraunhofer-Institute for Applied Polymer Research (IAP), Department of Healthcare, \\ Biomaterials and Cosmeceuticals, Potsdam, Germany \\ ${ }^{\mathrm{b}}$ QUESTALPHA GmbH \& Co.KG, Eschenburg, Germany
}

Received: 12 October 2020

Accepted: 19 October 2020

\begin{abstract}
.
BACKGROUND: Within the last years the investigation of cellulosic materials got into the focus of biomaterial research due to biocompatibility, sustainability, ubiquitous deposits and the potential of simple modification. Thereby this material is an ideal candidate to tailor material properties as charge, swelling, hydrophilicity and elasticity to clinical demands. OBJECTIVE: In this study a cellulose-based material was functionalized using plasma and gas $\left(\mathrm{O}_{2}, \mathrm{~N}_{2}\right.$, silane).

METHODS: The effect of material modification on two cell lines using different animal species was investigated using indirect and direct cytotoxicity analysis. The following parameters were investigated: number of adherent cells, cell viability, metabolic activity, cell membrane integrity and morphology.

RESULTS: Pristine and functionalized material eluates did not harm L929 cells and could be classified as non-cytotoxic according to DIN-EN-ISO 10993. A direct seeding of CHO-cells onto material surfaces showed a similar result. None of the conducted modifications had a negative effect on CHO-cells. Interestingly, parameters investigated during the study were positively influenced after material functionalization. In special, the treatment of cellulose with silane improved cell viability, metabolic activity, cellular adherence and cell membrane integrity significantly.

CONCLUSIONS: Within this study the potential of cellulose-based material functionalization with tailorable effects on different cell lines was proven. This indicates that all investigated medical grade sponge materials are promising polymers for applications in clinical routine.
\end{abstract}

Keywords: Cellulose, cytotoxicity analysis, L929 cells, CHO-cells, material modification, plasma

\section{Introduction}

Biomaterials are widely used for clinical applications as suture material, as orthopedic implant, as stent or vascular graft in the cardiovascular field, as wound dressing, oral implant or in regenerative medicine [1]. Depending on the application and medical needs biomaterials are composed of different materials like metals, ceramics or polymers. Several polymers which are applied used as implant materials were developed first for industrial use. Therefore, these materials do not fulfil all or only partly

\footnotetext{
*Corresponding author: Anne Krüger-Genge, Fraunhofer-Institute for Applied Polymer Research (IAP), Department of Healthcare, Biomaterials and Cosmeceuticals, Geiselbergstr. 69, 14476 Potsdam-Golm, Germany. Tel.: +49331 5681339; E-mail: anne.krueger-genge@iap.fraunhofer.de.
} 
the requirements needed for clinical applications such as biocompatibility or defined physicochemical properties matching the needs of the surrounding tissue [2]. In the worst case, this can contribute to the rejection of implants or major adverse events including death. Hence, it is an urgent need for the development of new biomaterials for clinical applications. Nowadays, the design of new biomaterials is also driven by principles of sustainability, eco-efficiency and green chemistry [3]. Therefore, cellulose moved into the focus of biomaterials research. Cellulose is a widespread biopolymer, which can be obtained from a huge number of sources such as plant cell walls, tunicates and bacteria [3]. Cellulose is known to be easily functionalized using exposed hydroxyl groups at the surface of fibrils [3]. Utilizing this special feature of cellulose a better adhesion and higher growth rates of fibroblasts or endothelial cells can be obtained after mannosylation of cellulosic surfaces or modification of nanocellulose using Xyloglucan-RGD conjugates $[4,5]$. The simple modification of cellulose surfaces offers a high potential for clinical or diagnostic applications. Currently cellulose is used in the food industry, for analytical procedures and as medical grade absorbent material. Focus of our study was the functionalization of a medical grade material (Sugi ${ }^{\circledR}$, Questalpha) consisted of natural cotton and cellulose in order to create non-cytotoxic materials with tailored surface properties to control cellular adhesion. Non-aqueous modification was used to preserve surface properties. A significant effect like increased cellular adhesion or cell selectivity would recommend the material for further analyses regarding compatibility with region-specific cells, enabling it as potential implant material or application in diagnostics. Within this study the following modifications of the cellulose sponges (Sugi ${ }^{\circledR}$ ) were carried out (hereinafter referred as KB-0): i.) plasma activation of cellulose with covalent grafting of ethylene oxide (EO) (hereinafter referred as KB-1), ii.) plasma treatment of cellulose with $\mathrm{O}_{2}$ (hereinafter referred as KB-7) and iii.) chemical vapor deposition after $\mathrm{N}_{2}$-plasma activation using methyldimethoxysilane (MDMS) (hereinafter referred as KB-9). After material modification, a pilot study was conducted using two different cell lines. In a first step the influence of material eluates on L929 cells were investigated (indirect cytotoxicity analysis) in order to detect potential toxic degradation products, leachables or other factors which could harm cells [6]. In a second step a direct incubation with Chinese hamster ovary cells ( $\mathrm{CHO}$ ), as a second animal species, was performed (direct cytotoxicity testing). The direct seeding of cell onto the different material surfaces was performed in order to determine harmful influences due to surface properties or toxic residues or physicochemical effects.

\section{Materials and methods}

\subsection{Material modification}

Cellulose sponges (Sugi®) were placed at disposal by courtesy of the company QUESTALPHA GmbH\&Co KG, Eschenburg (Germany). Plasma treatment was performed using a low-pressure plasma oven (Flecto 10, Plasma Technology GmbH, max. power $300 \mathrm{~W}$ at $40-100 \mathrm{kHz}$ ). Plasma exposure for $2 \mathrm{~min}$ in a 11.51 chamber, vacuum $0.2 \mathrm{mbar}$, gas flow $5 \mathrm{sccm}$ for $180 \mathrm{~s}\left(\mathrm{~N}_{2}\right.$ sourced from the laboratorium gas line and $\mathrm{O}_{2}$ from $51 \mathrm{O}_{2}$ concentrator Compact 525 from DeVilbiss Healthcare). Ethylene oxide (EO) treatment system consisted of a 0.51 steel autoclave connected on one side to a 0.31 EO steel cylinder purchased from Linde AG and on the other side to an outlet leading into gas-washing bottles filled with $2.5 \%$ aqueous sulfuric acid as neutralizing agent. EO pressure was 1.2-1.3 bar, leading to a concentration of $2.5 \mathrm{mg} . \mathrm{ml}^{-1} \mathrm{EO}$ in the reactor (ca. $0.5 \mathrm{~g}$ in $200 \mathrm{ml}$ volume). Silanation was performed in an desiccator with $700 \mathrm{ml}$ useable volume heated in a drying cabinet. Methyldimethoxysilane (MDMS, CAS-Nr.: 16881-77-9) was purchased from abcr GmbH, Germany. 


\subsection{Preparation of material eluate for indirect cytotoxicity testing}

The preparation of material eluates was performed according to the guidelines of the ISO standard 10993-12. $1 \mathrm{~g}$ of sterile, swollen materials were incubated in Minimum Essential Medium (MEM) with 5\% serum (Biochrom, Berlin, Germany) for $72 \mathrm{~h}$ at $37^{\circ} \mathrm{C}$ [7].

\subsection{Cultivation of L929 cells}

L929 cells (DSMZ, Braunschweig, Germany) were cultivated in MEM medium (Biochrom, Berlin, Germany) with serum. For cytotoxicity analysis cells were trypsinized (TrypLE Express Enzyme (1x), GibcoTM, Thermofisher Scientific, Berlin, Germany) and seeded on TCP (TPP, VWR, Darmstadt, Germany) in passage $5-8$ in MEM with 5\% serum for $24 \mathrm{~h}$. Subsequently MEM medium was removed and cells were cultivated in medium containing material eluates. As negative control (NC) L929-cells in MEM cultivated on TCP medium were used. As positive control (PC) L929-cells cultivated in MEM on TCP were used with specific treatment for each test system. The analysis of cytotoxicity according DIN-EN-ISO-10993-5 was performed after $48 \mathrm{~h}$ of incubation with the material eluate.

\subsection{Viability of L929 cells}

Viability of L929 cells was investigated using fluorescein diacetate (FDA, Sigma Aldrich, Darmstadt, Germany) to stain viable cells in green and propidium iodide (PI, Sigma Aldrich, Darmstadt, Germany) to stain dead cells in red after 48h of eluate incubation [8]. Adherent cells were incubated with $10 \mu$ $\mathrm{g} / \mathrm{ml} \mathrm{FDA}$ and $4 \mu \mathrm{g} / \mathrm{ml}$ PI for 3 minutes at $37^{\circ} \mathrm{C}$. Subsequently, each sample was analyzed at three different fields of view using fluorescence microscopy (Leica DMI 3000B; Wetzlar, Germany) in 10x primary magnification.

\subsection{Metabolic activity of cells}

The analysis of the metabolic activity of cells was performed using CellTiter 96® Aqueous NonRadioactive Cell Proliferation Assay (Promega, Walldorf, Germany) according to manufacturer's instructions [9]. L929 cells were analyzed after 48 hours of material eluate incubation onto cells, CHO-cells were analyzed 48 and $96 \mathrm{~h}$ after cell seeding on materials surface.

\subsection{Cell membrane integrity}

Cell membrane integrity was measured after 48h (L929 cells; CHO-cells) and 96h (CHO-cells). The analysis was performed using LDH-Cytotoxicity Colorimetric Assay Kit II (Biovision, Ilmenau, Germany) according to manufacturer's instructions.

\subsection{Cultivation of $\mathrm{CHO}$ cells for direct cytotoxicity analysis}

Chinese hamster ovary cells (CHO, DSMZ, Braunschweig, Germany) were cultivated in Ham's F12 with serum (Bio\&Sell, Feucht, Germany). For the analysis of cell-material interaction, $\mathrm{CHO}$ cells were seeded in passage 11 on the swollen cellulose-based materials $(n=6)$ for a maximum of 4 days. Cell culture medium was changed $48 \mathrm{~h}$ after cell seeding. 


\subsection{Cell number and cell viability of $\mathrm{CHO}$ cells}

In order to determine cell number and viability cellulose materials were incubated 48 and $96 \mathrm{~h}$ after cell seeding with trypsin/EDTA (Bio\&Sell, Feucht, Germany) for 5 minutes with subsequent centrifugation and resuspension of the cell pellet in Ham's F12 with 9\% FBS (Bio\&Sell, Feucht, Germany). Cell number and cell viability were detemined using Innovatis Casy Cell counter (Biovendis, Mannheim, Germany).

\subsection{Immunocytochemical staining of F-actin}

48 and $96 \mathrm{~h}$ after cells seeding CHO-cells were fixed with $4 \%$ formaldehyde. Subsequently, Phalloidin-iFluor (abcam, Cambridge, USA) was applied according to manufacturer's instructions [10].

\subsection{Microscopy}

The morphology of L929 and fluorescence of CHO cells were assessed using phase contrast microscopy or fluorescence microscopy (Leica DMI 3000B; Wetzlar, Germany) in 10x primary magnification.

\subsection{Statistical analysis}

For all samples arithmetic mean and standard deviation is given. Statistical analysis was performed using GraphPad Prism 8 (San Diego, USA). For two sample problems two-sided student's $t$-test for unpaired samples was used. Statistical differences were considered significant if $p<0.05$.

\section{Results}

\subsection{Indirect cytotoxicity analysis of Sugi ${ }^{\circledR}$ eluates}

In order to investigate the cytotoxicity of the conducted material modifications an analysis of the material eluates was performed (DIN-EN-ISO-10993-5, indirect cytotoxicity analysis). Eluates were incubated with L929 cells for $48 \mathrm{~h}$. Thereafter cell number, cell viability, metabolic activity, cell membrane integrity and cell morphology were analyzed. Subsequently, a final assessment regarding the cytotoxicity according to the ISO standard was accomplished. Cells cultivated on TCP in pure cell culture medium were used as negative control (NC). As positive control (PC) cells cultivated on TCP with subsequent treatment using assay specific control were used.

\subsection{Cell viability}

The viability of L929 cells cultivated with the eluate of KB-0, KB-1 and KB-7 was comparable with the viability of untreated control cells (NC) with approximately $99 \%$. Cells cultivated with eluates of KB-9 exhibited with $98.8 \%$ a slightly reduced cell viability $(p<0.05)$ (Fig. 1). 


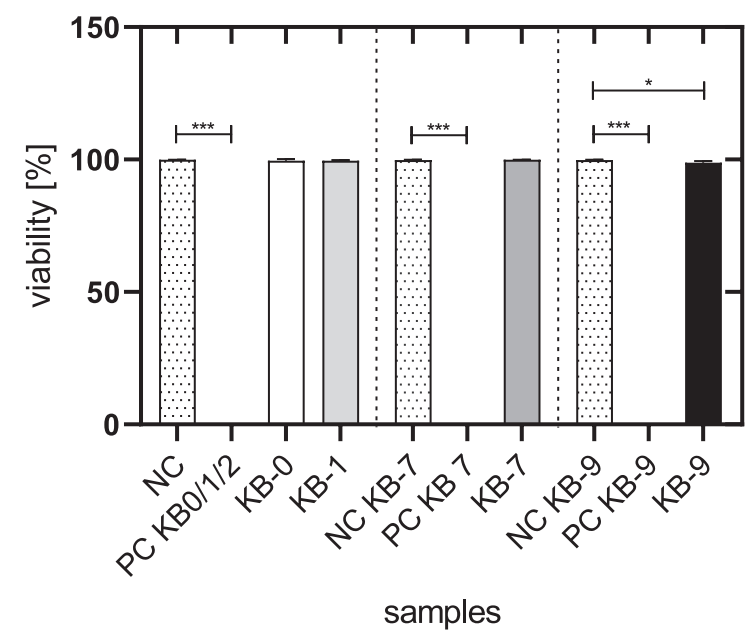

Fig. 1. Cell viability of L929 cells after $48 \mathrm{~h}$ of eluate incubation with KB-0, KB-1, KB-7 and KB-9. L929 cells cultivated with pure medium were used as negative control (NC). Cells cultivated in TCP and treated with Triton X-100 were used as positive control (PC). Presented are arithmetic mean \pm standard deviation of $n=9-12$ samples. $p<0.05$ was considered significant compared to NC. *: $p<0.05 ; * *$ : $p<0.01, * * *: p<0.001$.

\subsection{Number of adherent cells}

The number of adherent $\mathrm{L} 929$ cells per $\mathrm{mm}^{2}$ was significantly reduced for all samples compared to $\mathrm{NC}$ after $48 \mathrm{~h}$ of eluate incubation (KB-0:804 \pm 95 per mm ${ }^{2}, \mathrm{~KB}-1: 760 \pm 79$ per mm$^{2}, \mathrm{~KB}-7: 1826 \pm 71$ per $\mathrm{mm}^{2}, \mathrm{~KB}-9: 348 \pm 37$ per $\mathrm{mm}^{2}$, NC: $1417 \pm 42$ per $\left.\mathrm{mm}^{2}\right)(p<0.05$ each).

\subsection{Cell membrane integrity}

The analysis of cell membrane integrity was investigated by measuring the release of lactate dehydrogenase (LDH) from the L929 cells in the cell culture supernatant. An incubation of L929 cells with eluates of KB-0 und KB-1 showed a comparable release of LDH in the cell culture supernatant. In contrast, a significant higher release of $\mathrm{LDH}$ was detected for $\mathrm{L} 929$ cells cultivated with eluates of KB-7 and KB-9 $(p<0.05$ each) (Fig. 2).

\subsection{Metabolic activity}

The metabolic activity of L929 cells was not affected for KB-1, KB-7 and KB-9 and thereby comparable with NC (Fig. 3). A significantly reduced metabolic activity of L929 cells was only seen for KB-0 compared to control cells $(p<0.05)$.

\subsection{Cell morphology}

According to DIN-EN_ISO 10993-5 the morphology of L929 was investigated regarding cell lysis, occurence of intracellular granules and impairment of cell growth (cell monolayer formation) (Fig. 4). No significant alterations were observed for L929 cells incubated with eluates of KB-0, KB-1 and KB7 compared to control cells. An increased occurence of intracellular vacuoles was seen after contact with KB-9 eluate indicating cellular stress. 


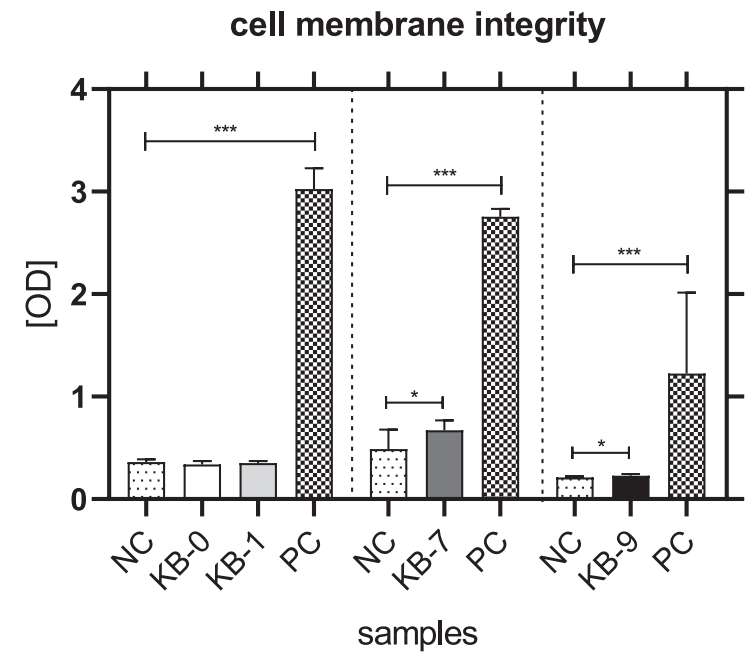

Fig. 2. Cell membrane integrity of L929 cells after $48 \mathrm{~h}$ of eluate incubation with KB-0, KB-1, KB-7 and KB-9 measured in three independent studies. L929 cell cultivated with pure medium (NC) were used as negative control (NC). Cells cultivated in TCP and treated with cell lysis buffer were used as positive control (PC). Presented are arithmetic mean \pm standard deviation of $n=8$ samples. $p<0.05$ was considered significant compared to NC. *: $p<0.05 ; * *: p<0.01, * * *: p<0.001$.

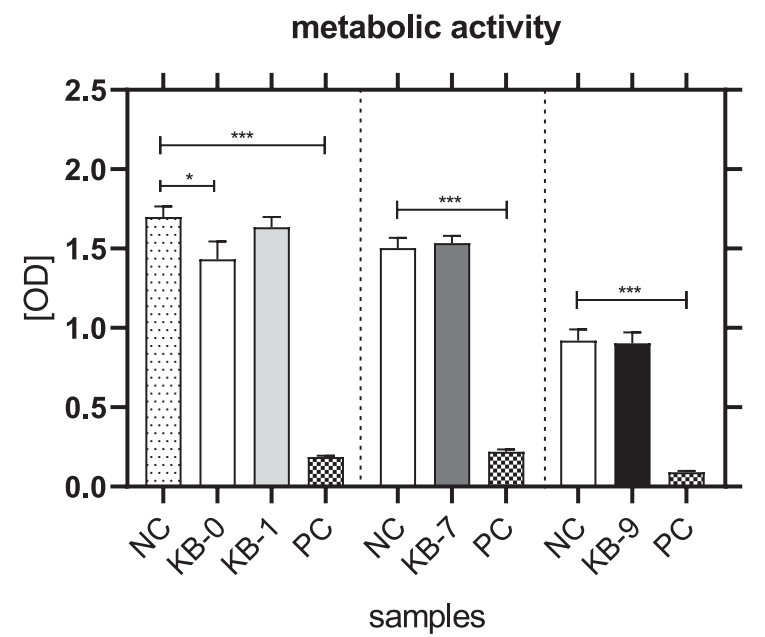

Fig. 3. Metabolic activity of L929 cells after $48 \mathrm{~h}$ of eluate incubation with KB-0, KB-1, KB-7 and KB-9 measured in three independent studies. L929 cell cultivated with pure medium (NC) were used as negative control (NC). Cells cultivated in TCP and treated with cell lysis buffer were used as positive control (PC). Presented are arithmetic mean \pm standard deviation of $n=8$ samples. $p<0.05$ was considered significant compared to NC. *: $p<0.05 ; * *: p<0.01, * * *: p<0.001$.
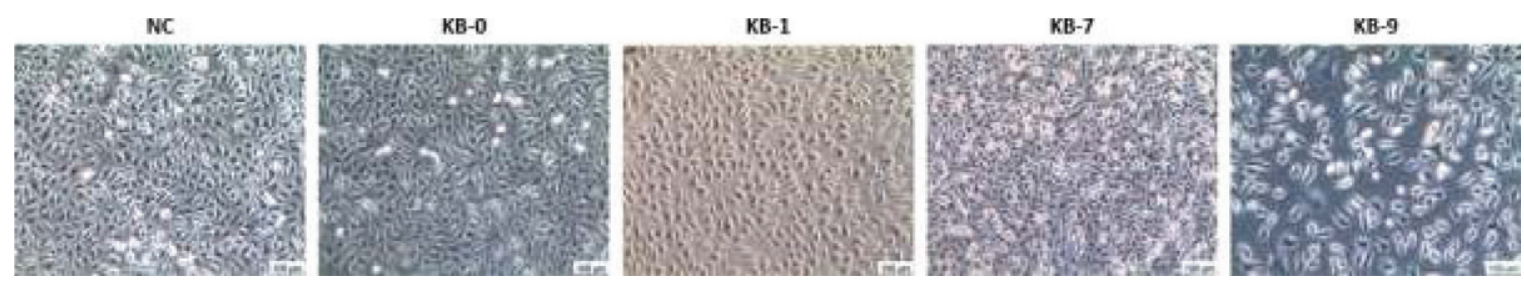

Fig. 4. Representative images of L929 cell morphology after $48 \mathrm{~h}$ of eluate incubation. Phase contrast microscopy in 10x primary magnification. 


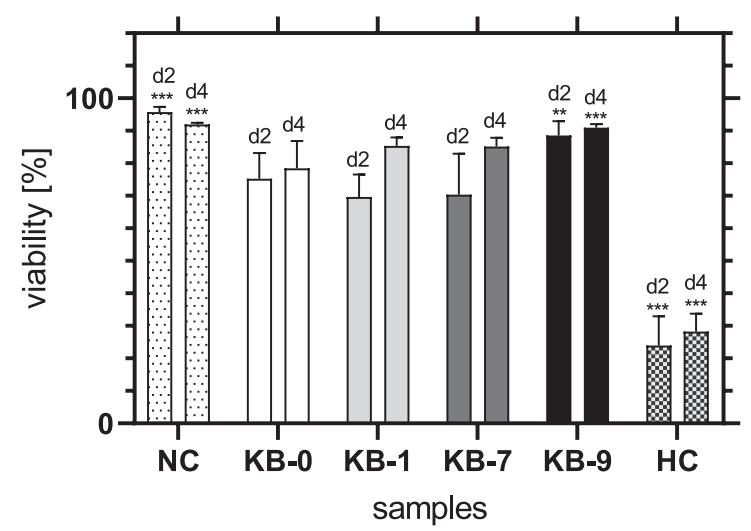

Fig. 5. Viability of adherent CHO cells two and four days after cell seeding on TCP (NC), KB-0, KB-1, KB-7 and KB-9. Shown are arithmetic mean \pm standard deviation of $n=4-6$. Statistical significance was analyzed using $t$-test analysis. $p<0.05$ was considered significant compared to KB- $0 *: p<0.05, * *: p<0.01, * * *: p<0.001$.

The analysis of cell number, cell viability, metabolic activity, cell membrane integrity and cell morphology according to the ISO standard revealed that KB-0, KB-1, KB-7 and KB-9 can be classified as non (KB-1) or weak (KB-0, KB-7, KB-9) cytotoxic according to the criteria of the DIN-EN_ISO 10993-5 after testing of material eluates with L929 cells. In conclusion, all materials (with and without modification) passed the cytotoxicty analysis according to DIN-EN_ISO 10993-5 with a cytotoxicity grade of $0-1$.

\subsection{Compatibility of modified Sugi ${ }^{\circledR}$ with $\mathrm{CHO}$-cells (direct cytotoxicity)}

The compatibility of cells with the pristine or functionalized Sugi ${ }^{\circledR}$ was investigated with Chinese hamster ovary cells (CHO-cells) after direct seeding onto the material surface. The number of adherent cells, cell viability, damage of cell membrane integrity, metabolic cell activity and cell morphology were investigated two and four days after cell seeding. Cells cultivated on KB-0 were used as control.

\subsection{Analysis of cell viability}

The viability of CHO-cells on KB-1 and KB-7 increased continuously over time and did not differ significantly from KB-0 (Fig. 5). An increase of cell viability was also seen for KB-9, whereas the viability of cells was significantly higher compared to KB-0 for both 2 and 4 days after cell seeding (d2: $p<0.01, \mathrm{~d} 4: p<0.001)$. Thus, it can be summarized, that none of the modifications had a negative influence on the viability of CHO-cells after direct material contact.

\subsection{Analysis of cell membrane integrity}

Cell membrane integrity was measured by release of LDH in the cell culture supernatant. A significant reduced release of LDH and thereby less membrane damage was observed for all samples modified compared to pristine Sugi ${ }^{\circledR}$ after $48 \mathrm{~h}$ of cell seeding (NC: $p<0.05, \mathrm{~KB}-1: p<0.01, \mathrm{~KB}-7$ : $p<0.001$ ) (Fig. 6). This result was also obtained for KB-7 and KB-9 four days after cell seeding (KB-7: $p<0.05$, KB-9: $p<0.01)$. CHO-cells cultivated on KB-1 showed a similar release of LDH compared to unmodified KB-0. 


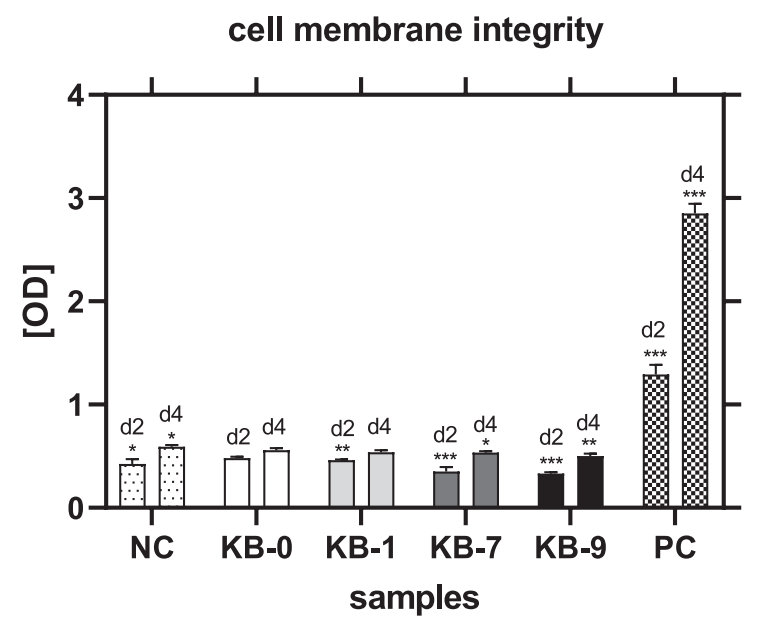

Fig. 6. Cell membrane integrity of CHO cells on TCP (NC), KB-0, KB-1, KB-7 and KB-9 two and four days after cell seeding. Shown are arithmetic mean \pm standard deviation of $n=6$. Statistical significance was analyzed using $t$-test analysis compared to KB-0..*: $p<0.05, * *: p<0.01, * * *: p<0.001$.

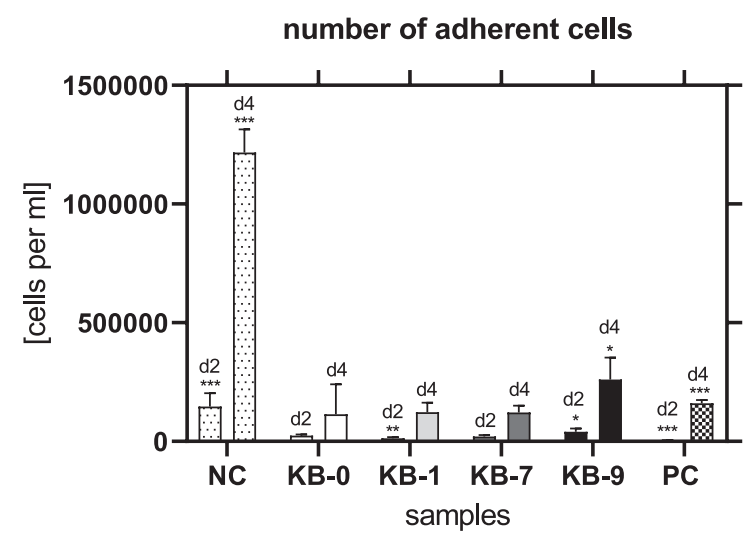

Fig. 7. Number of adherent cells two and four days after cell seeding on TCP (NC), KB-0, KB-1, KB-7 and KB-9. Shown are arithmetic mean \pm standard deviation of $n=6$. Statistical significance was analyzed using $t$-test analysis compared to KB-0. $*: p<0.05, * *: p<0.01, * * *: p<0.001$.

\subsection{Number of adherent cells}

The number of adherent cells was comparable for KB-0 and KB-7 two and four days after cell seeding. In contrast, KB-1 showed a significant reduced number of cells after two days of cell seeding $(p<0.01)$ while a significant higher number of cells was found on KB-9 $(p<0.05)$ (Fig. 7). Four days after cell seeding a significant higher cell number was found on KB-9 $(p<0.05)$, while the number of CHO cells was comparable with the control KB-0 for KB-1 and KB-7.

\subsection{Analysis of metabolic activity}

$48 \mathrm{~h}$ after cell seeding on Sugi ${ }^{\circledR}$ a similar metabolic activity of $\mathrm{CHO}$ cells was observed for KB-1 and KB-7 compared to KB-0 as control (Fig. 8). Cells cultivated on KB-9 showed an increased metabolic activity compared to KB-0 $(p<0.001)$, which was in accordance with the number of adhered cells. 


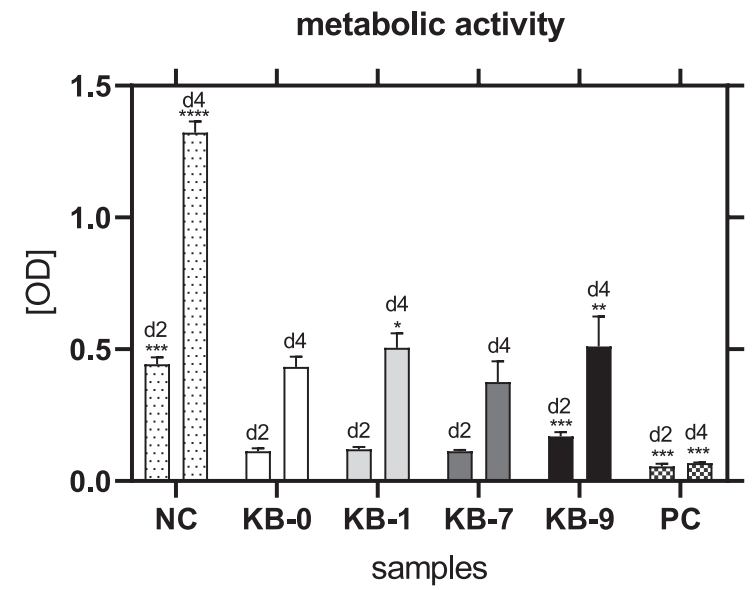

Fig. 8. Metabolic activity of CHO cells two and four days after cell seeding on TCP (NC), KB-0, KB-1, KB-7 and KB-9. Shown are arithmetic mean \pm standard deviation of $n=6$. Statistical significance was analyzed using $t$-test analysis compared to KB-0. $*: p<0.05, * *: p<0.01, * * *: p<0.001$.

A comparable metabolic activity was seen for $\mathrm{CHO}$ cells cultivated on KB-0 and KB-7 $96 \mathrm{~h}$ after cell seeding. $\mathrm{CHO}$ cells seeded on KB-1 and KB-9 exhibited a significant increased metabolic activity (KB-1: $p<0.05$; KB-9: $p<0.01$ ). Thus, none of the surface modifications had a negative influence on the metabolic activity of $\mathrm{CHO}$ cells.

\subsection{CHO cell morphology on pristine or modified cellulose-based Sugi® materials}

The staining of the actin cytoskeleton showed a direct adhesion of the cells on the fibre structures after two and four days of cell seeding (Fig. 9). Round, only weakly spreaded cells with developed stress fibres were observed indicating a strong attachment onto the material surface. Furthermore, it was observed that $\mathrm{CHO}$ cells wer also associated within the material cavities.

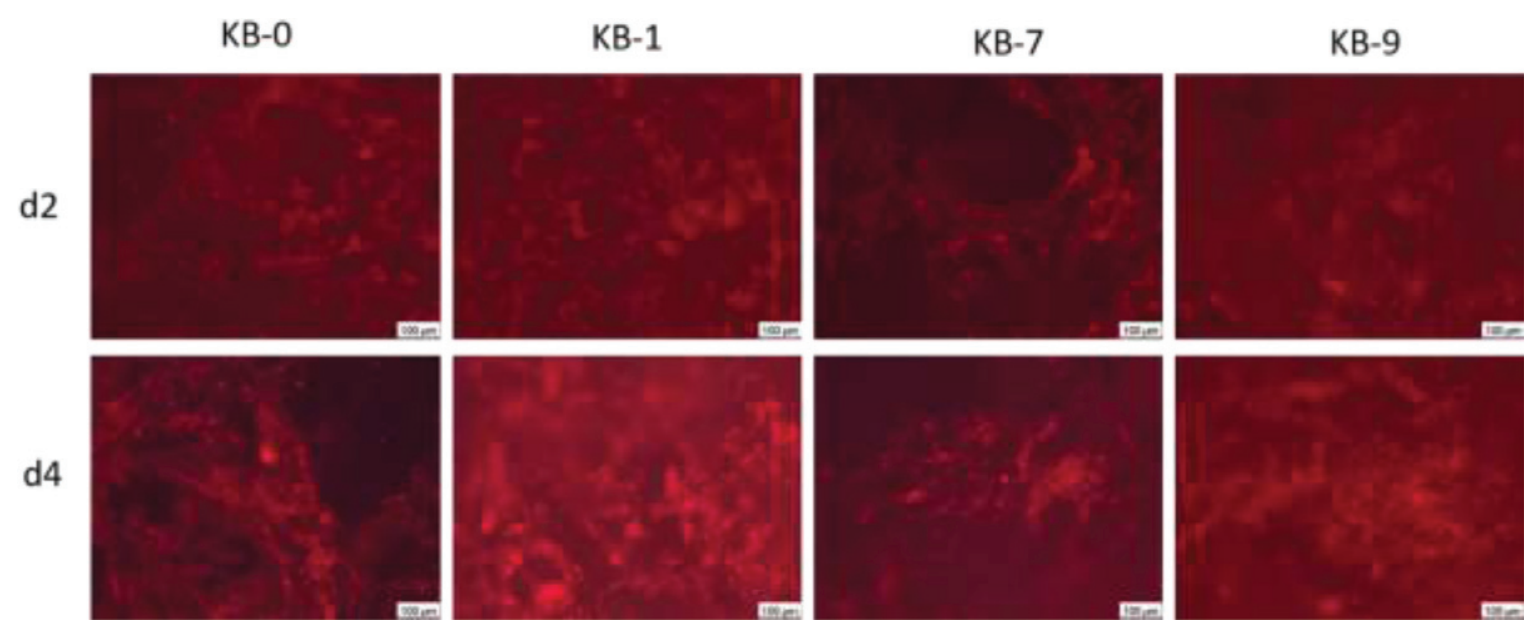

Fig. 9. Representative images of CHO cells 48 and $96 \mathrm{~h}$ after cell seeding on cellulose based material surfaces. Wide-field fluorescence microscopy, 10x primary magnification. CHO cells are stained using phalloidin (red). 


\section{Discussion}

The development of new biomaterials for specific applications with tailored properties for tissue engineering, implantation or wound dressing is currently in the focus of biomaterial research [11-13]. In addition to the requirements regarding their specific application in respect to biocompatibility, degradability, product safety, clinical and commercial endpoint further demands as sustainability play an important role $[14,15]$. Thus, cellulose-based materials for application in life sciences get into the focus of research [16]. Cellulose is a biocompatible biopolymer with abundant ressources which can be obtained easily and cheap [17]. Due to favorable surface charges it can be functionalized in a simple way. Therefore, cellulose is an appropriate candidate material for use in clinical. In this study a cellulose-based material (Sugi ${ }^{\circledR}$ ) currently used as absorbent material during surgery was tested regarding a further application after various functionalizations. Functionalizations were focused on rendering the material surfaces hemo- or tissue-compatible by controlling the adherence of proteins and cells. Therefore, polyethylene glycol (PEG), oxygenated reactive groups and methyl groups with increased hydrophobicity were introduced [18] using plasma activation and various gases. In a first step, the modifications were investigated using an indirect cytotoxicity test according to the ISO standard 10993-5/12. Within this analysis toxic degradation products or leachables were investigated using an eluate of the material. All materials investigated - pristine and functionalized - could be classified as non cytotoxic according to the ISO standard 10993-5 [19]. Interestingly, the number of adherent L929 cells was significantly reduced for all Sugi ${ }^{\circledR}$ materials compared to the negative control, while the viability of cells was $99 \%$. A delayed proliferation was seen also in a former study using stromal osteoblastic cells seeded on bacterial cellulosic material [20]. L929 cells - also used in this study - did not show a reduced number of adherent cells which is in contrast to our study. Although the number of cells was reduced in our analyis, the cells stayed vital so that a harmful effect of the materials (pristine, modified) can be excluded. A possible explanation for the differing results could be the utilization of bacterial cellulose. Within our study cellulose obtained from plants was used. Although the proliferation of stromal osteoblastic cells was delayed, the final assessment of the cellulose investigated was in accordance to the materials used in our studies; both materials were classified as non-cytotoxic. It has to be emphazised that during the indirect cytotoxicity testing material topography and further material properties do not have an influence on material toxicity. These parameters are only important in case of direct cell seeding onto material surfaces. Thereafter, the direct contact of $\mathrm{CHO}$ cells - another cell type from a different species - with the material surface was investigated in order to analyze possible toxic effects due to the surface structure and changes of physicochemical properties after material functionalization. None of the functionalizations had a negative effect on $\mathrm{CHO}$ cells after 48 and $96 \mathrm{~h}$ of incubation compared to the pristine material. Interestingly, a significant increased cellular adherence, viablity, metabolic activity and cell membrane integrity was observed after material treatment with plasma and silane (KB-9). An explanation could be the increased occurence of methyl groups after modification which can improve the adherence of cells. A similar effect was observed by Arima et al. [21]. In addition, the group of Arima et al. also reported that the presence of oxygenated reactive groups supported the adherence of cells. Within our study, we did not observe a significant difference between $\mathrm{CHO}$ cells cultivated on pristine Sugi ${ }^{\circledR}$ in comparison to plasma and $\mathrm{O}_{2}(\mathrm{~KB}-7)$ functionalized materials affecting material hydrophilicity by generating oxygenated functional groups like hydroxyl- or carboxyl-groups. A possible explanation could be a differing contact angle between the investigated samples which is known to affect cellular adherence [22]. Lee et al. demonstrated that the improved adherence of cells, regardless from cell type was seen for materials with moderate hydrophilicity. In contrast, Jaganja et al. demonstrated an increased adherence of human osteosarcome cells on hydrophobic, plasma-treated materials [23]. Similar to our study an increased metabolic activity of osteosarcome cells were seen on the functionalized materials. In addition, a delayed cell 
adhesion onto the material surface was observed. Within our study we did not find a delayed adhesion of $\mathrm{CHO}$ cells on Sugi ${ }^{\circledR}$ after direct material contact (only during the indirect cytotoxicity test), but for all materials a formation of stress fibers after 48 and $96 \mathrm{~h}$ of cell seeding was observed. The formation of stress fibers as component of the cytoskeleton is induced by an interaction between biomaterials and cells. The interaction between Sugi ${ }^{\circledR}$ and $\mathrm{CHO}$ cells occurs by utilizing the fibrous, spongious structure of the material. So, the formation of stress fibers is a good sign for the interaction of cells with the biomaterial on the material fibers or in the cavities. In addition, the increasing number of cells independent from the material substrate is a good sign as well since proliferation of adherent cells is strongly related to material contact $[24,25]$. A significantly increased cell number was only observed for $\mathrm{CHO}$-cells cultivated on KB-9. A possible reason could be the surface charge. While a more negatively charged surface was created due to oxygenated plasma treatment on KB-7 a charge-free surface was created on KB-9. Since cells are charged negatively on average a charge free surface could support cellular adherence. The group of Lee et al. showed, that negatively charged substrates have an influence on the growth of cells [26]. In summary, none of the functionalized materials had a negative effect using a material eluate according to ISO standard 10993-5/12 on L929 cells, nor on CHO-cells after direct contact of the cells with the material surfaces. Thereby all materials can be classified as non-cytotoxic and compatible with the cells used for the respective test systems. In addition, it could be shown, that the modifications performed can be used to control the adherence of cells onto the material surface. Furthermore, it was clearly shown that certain modifications improved cell adherence, viability, metabolic activity and cell membrane integrity. Whether the modified materials can also be used to control protein adsorption will be analysed in future studies. In addition, further studies are planned in order to investigate the compatibility of the materials (pristine, functionalized) with human primary cells. Furthermore, a deeper characterization of material surface properties will be conducted to analyze the interactions of the materials' surface with proteins and cells in relation to the material characteristics.

\section{Conclusions}

It can be summarized that Sugi ${ }^{\circledR}$, a medical-grade material which is already used as absorbent in clinical routine, is an optimal candidate material for further applications as implant or for utilization as diagnostic tool.

\section{Author contributions}

Conceptualization, A.K.G., J.S. and W.M.; methodology, A.K.G., S.W., S.K., O.M.; software, A.K.G.; validation, A.K.G., J.B., and J.S.; formal analysis, A.K.G., J.B., J.S.; investigation, S.W., S.K., A.K.G.; resources, S.W., S.K., O.M.; data curation, A.K.G., S.W., S.K.; writing-original draft preparation, A.K.G.; writing-review and editing, J.B., J.S.; visualization, A.K.G., J.B., S.W., S.K.; supervision, A.K.G.; project administration, J.S.; funding acquisition, Y.Y. All authors have read and agreed to the published version of the manuscript.

\section{Conflicts of interest}

The authors declare no conflict of interest. 


\section{Funding}

This research received no external funding.

\section{References}

[1] Feng K, Wei W, Yang C, Dong S. Directly use conductive materials in tissue engineering applications. Journal of Cellular Biotechnology. 2020;6:23-46.

[2] Klopfleisch R, Jung F. The pathology of the foreign body reaction against biomaterials. J Biomed Mater Res A. 2017;105(3):927-40.

[3] Courtenay JC, Sharma RI, Scott JL. Recent Advances in Modified Cellulose for Tissue Culture Applications. Molecules. 2018;23(3):654.

[4] Birkheur S, Faria-Tischer PCdS, Tischer CA, Pimentel EF, Fronza M, Endringer DC, et al. Enhancement of fibroblast growing on the mannosylated surface of cellulose membranes. Materials Science and Engineering: C. 2017;77:672-9.

[5] Bodin A, Ahrenstedt L, Fink H, Brumer H, Risberg B, Gatenholm P. Modification of Nanocellulose with a Xyloglucan-RGD Conjugate Enhances Adhesion and Proliferation of Endothelial Cells: Implications for Tissue Engineering. Biomacromolecules. 2007;8(12):3697-704.

[6] Krüger-Genge A, Schmidt C, Storsberg J. Chocolate cream labels as novel potential biomaterial? About red herrings in the scientific biomaterial scene. Journal of Cellular Biotechnology. 2019;5:1-2.

[7] Battig A, Hiebl B, Feng Y, Lendlein A, Behl M. Biological evaluation of degradable, stimuli-sensitive multiblock copolymers having polydepsipeptide- and poly ( $\varepsilon$-caprolactone) segments in vitro. Clinical hemorheology and microcirculation. 2011;48:161-72.

[8] Schulz C, Krüger-Genge A, Jung F, Lendlein A. Aptamer supported in vitro endothelialization of poly(ether imide) films. Clin Hemorheol Microcirc. 2020;75(2):201-17.

[9] Krüger-Genge A, Steinbrecht S, Küpper JH, Lendlein A, Jung F. Evidence for cytostatic effect of cyclophosphamide on human vein endothelial cells in cancer therapy: Preliminary in vitro results. Clin Hemorheol Microcirc. 2018;69(12):267-76.

[10] Krüger-Genge A, Braune S, Walter M, Krengel M, Kratz K, Küpper JH, et al. Influence of different surface treatments of poly(n-butyl acrylate) networks on fibroblasts adhesion, morphology and viability. Clin Hemorheol Microcirc. 2018;69(1-2):305-16.

[11] Narayan RJ. The next generation of biomaterial development. Philos Trans A Math Phys Eng Sci. 2010;368(1917): 1831-7.

[12] Nih LR. Engineered Biomaterials for Tissue Regeneration of Innervated and Vascularized Tissues: Lessons Learned from the Brain. Journal of Endodontics. 2020;46(9, Supplement):S101-S4.

[13] Braune S, Latour RA, Reinthaler M, Landmesser U, Lendlein A, Jung F. In Vitro Thrombogenicity Testing of Biomaterials. Advanced Healthcare Materials. 2019;8(21):1900527.

[14] Williams DF. Challenges With the Development of Biomaterials for Sustainable Tissue Engineering. Frontiers in Bioengineering and Biotechnology. 2019;7(127).

[15] Ullm S, Krüger A, Tondera C, Gebauer TP, Neffe AT, Lendlein A, et al. Biocompatibility and inflammatory response in vitro and in vivo to gelatin-based biomaterials with tailorable elastic properties. Biomaterials. 2014;35(37):9755-66.

[16] Hoenich N, editor CELLULOSE FOR MEDICAL APPLICATIONS: PAST, PRESENT, AND FUTURE2006.

[17] Modulevsky DJ, Cuerrier CM, Pelling AE. Biocompatibility of Subcutaneously Implanted Plant-Derived Cellulose Biomaterials. PLoS One. 2016;11(6):e0157894.

[18] Neffe AT, von Rüsten-Lange M, Braune S, Lützow K, Roch T, Richau K, et al. Multivalent grafting of hyperbranched oligo- and polyglycerols shielding rough membranes to mediate hemocompatibility. J Mater Chem B. 2014;2(23):362635.

[19] Battig A, Hiebl B, Feng Y, Lendlein A, Behl M. Biological evaluation of degradable, stimuli-sensitive multiblock copolymers having polydepsipeptide- and poly $+\mu$-caprolactone) segments in vitro. Clinical hemorheology and microcirculation. 2011;48(1):161-72.

[20] Chen YM, Xi T, Zheng Y, Guo T, Hou J, Wan Y, et al. In Vitro Cytotoxicity of Bacterial Cellulose Scaffolds Used for Tissue-engineered Bone. Journal of Bioactive and Compatible Polymers. 2009;24(1_suppl):137-45.

[21] Arima Y, Iwata H. Effect of wettability and surface functional groups on protein adsorption and cell adhesion using well-defined mixed self-assembled monolayers. Biomaterials. 2007;28(20):3074-82.

[22] Lee JH, Khang G, Lee JW, Lee HB. Interaction of Different Types of Cells on Polymer Surfaces with Wettability Gradient. Journal of Colloid and Interface Science. 1998;205(2):323-30. 
[23] Jaganjac M, Milkovic L, Cipak A, Mozetic M, Recek N, Vesel A. Cell Adhesion On Hydrophobic Polymer Surfaces. Materiali in Tehnologije. 2012;46:53-6.

[24] Vivas J, Garzón-Alvarado D, Cerrolaza M. Modeling cell adhesion and proliferation: a cellular-automata based approach. Advanced Modeling and Simulation in Engineering Sciences. 2015;2(1):32.

[25] Modulevsky DJ, Lefebvre C, Haase K, Al-Rekabi Z, Pelling AE. Apple derived cellulose scaffolds for 3D mammalian cell culture. PLoS One. 2014;9(5):e97835.

[26] Lee JH, Jung HW, Kang I-K, Lee HB. Cell behaviour on polymer surfaces with different functional groups. Biomaterials. 1994;15(9):705-11. 